\title{
Erratum to: Optimal mixed taxation, public goods and the problem of high-skilled emigration
}

\author{
X. Ruiz del Portal ${ }^{1}$
}

Published online: 14 September 2017

(C) Springer-Verlag GmbH Austria 2017

\section{Erratum to: J Econ DOI 10.1007/s00712-017-0536-6}

We regret that in the original publication of the article, some equations were incorrectly published. A number of typesetting errors, mainly spacing errors, have been fixed in the article to improve the readability.

The original article was corrected.

The online version of the original article can be found under doi:10.1007/s00712-017-0536-6.

$凶 \quad$ X. Ruiz del Portal rportal@econap.udl.cat

1 Department of Applied Economics, University of Lleida, Lleida, Spain 